\title{
To flee or not to flee: detection, avoidance of and attraction to food resources by Daphnia magna studied with an olfactometer
}

\author{
Johann P. MÜLLER,, $2^{1,2}$ David LALOI, ${ }^{3}$ Claude YÉPRÉMIAN,${ }^{4}$ Cécile BERNARD,${ }^{4}$ Florence D. HULOT ${ }^{5}$ \\ ${ }^{1}$ UMR 7618 Biogéochimie et écologie des milieux continentaux, UPMC, ENS, CNRS, IRD, U, PEC, AgroParisTech, Paris Cedex 05; \\ ${ }^{2}$ UFR Sciences de la Vie, UPMC Université Paris 06, Paris; ${ }^{3}$ UMR 7625 Ecologie et Evolution, UPMC Université Paris 06, Ecole Nor- \\ male Supérieure, AgroParisTech, CNRS, 7 quai Saint Bernard, 75005 Paris; ${ }^{4}$ UMR 7245 CNRS, MNHN Molécules de Communication \\ et Adaptation des Microorganismes, Muséum National d'Histoire Naturelle, 57 rue Cuvier, 75231 Paris Cedex 05; ${ }^{5}$ UMR 8079 Ecologie, \\ Systématique et Evolution, CNRS, Université Paris Sud, Orsay Cedex 91405, France
}

*Corresponding author: jmuller@biologie.ens.fr

\begin{abstract}
The cladoceran herbivore Daphnia magna is a major consumer of phytoplankton in lakes. Therefore, this organism may control the phytoplankton community and the proliferation of some algae or cyanobacteria. Cladoceran behaviour and migration in relation to temperature, light or presence of planktivorous fishes have been well studied. In particular, it is known that the detection of kairomones produced by predators may induce avoidance. Avoidance could also occur with other semiochemicals such as cyanotoxins. In order to explore this hypothesis, we used an olfactometer to observe and measure the exploratory behaviour of $\mathrm{D}$. magna individuals based on the motivation for food. Daphnids were allowed to choose between different compounds: water, a pure cyanotoxin, i.e. the microcystin$R R$ [(MC)-RR], extracts of one MC-producing strain (PMC 75.02) and one MC-free strain (PMC 87.02) of Planktothrix agardhii, or a green algae Scenedesmus obliquus. With this experimental design, we observed that i) cladocerans are able to detect resources with different qualities, ii) they can explore before exhibiting preferences, and iii) daphnids are able to avoid compounds that are potentially toxic (e.g., microcystins). First, daphnids explored the environment, subsequently (after about $1.5 \mathrm{~h}$ ), they showed a significant tendency to stay where there is a profitable resource such as $\mathrm{S}$. obliquus. These results also suggest that specimens of D. magna cannot detect $M C$ compounds from $\mathrm{P}$. agardhii, but they respond to it as a food resource. The study of zooplankton ability to explore the environment when exposed to semiochemicals needs further investigation.
\end{abstract}

Key words: Daphnia magna, Planktothrix agardhii, olfactometer, migration, secondary metabolites, cyanotoxins.

Received: August 2012. Accepted: March 2013.

\section{INTRODUCTION}

Relationships between cyanobacteria and zooplankton are complex and affect aquatic ecosystems acting as positive or negative controls in microorganism communities (Ghadouani et al., 2006; Oberhaus et al., 2007). Cyanobacteria are considered as inadequate food for zooplankton such as daphnids (Wilson et al., 2006). Indeed, i) cyanobacteria may be deficient in essential nutrients for zooplankton (De Bernardi and Giussani, 1990; MüllerNavarra et al., 2000; Von Elert and Wolfram, 2001), and ii) some cyanobacteria are known to produce toxic metabolites (e.g., cyanotoxins) that may harm or kill not only animals and humans (Carmichael, 1992; Hitzfield et al., 2000; Codd et al., 2005; Dittmann and Wiegand, 2006; Purdie et al., 2009) but also daphnids and other zooplankton (Rohrlack et al., 1999). Cyanotoxins may have various effects on zooplankton: decrease of swimming activity of freshwater cladocerans (Ferrao-Filho et al., 2007), inhibition of digestive enzymes (Arnold, 1971; Nogueira et al., 2006), inhibition of feeding rate, growth and reproduction (Arnold, 1971; Hawkins and Lampert, 1989; DeMott, 1999), decrease of weight (Gliwicz and Lampert, 1990) or even lethally toxic effect (Nogueira et al., 2004). These results, however, vary with experimental conditions (Lampert, 1987; Tillmanns et al., 2008). Among the many parameters which may influence these impacts we found: i) density of the food provided to Daphnia (Kurmayer, 2001), ii) temperature and viscosity of the water (Abrusán, 2004), iii) size of the zooplankton (Hawkins and Lampert, 1989; Kirk and Gilbert, 1992), iv) species of the grazer (Kirk and Gilbert, 1992), v) species and strains of cyanobacteria (Nogueira et al., 2006; Wilson et al., 2006; Tillmanns et al., 2008), or vi) type of metabolites provided (Nogueira et al., 2006).

Among toxic secondary metabolites, cyanotoxins microcystins (MC) are the most abundant ones. Still, several studies have shown that other compounds produced by cyanobacteria can have a negative impact on zooplankton as well (Kurmayer, 2001; Reinikainen et al., 2002; Lürling, 2003a; Rohrlack et al., 2004; Wilson and Hay, 2007; Hulot 
et al., 2012). Although the biological role of these compounds is debated (Schatz et al., 2007), one hypothesis is their negative effect on planktonic herbivores (Lürling, 2003b). Indeed, through its predatory activity, herbivorous zooplankton, and particularly Daphnia sp., has a direct impact on phytoplankton (Vanni, 1987; Vanni and Findlay, 1990; Hansson and Carpenter, 1993; Brett and Goldman, 1996; Oberhaus et al., 2007). Daphnia sp. is a major predator of algae (Kerfoot and Sih, 1987) and, in the absence of fish, zooplankton increases and phytoplankton decreases as a result of cascading trophic interactions (Christoffersen et al., 1993). Therefore, the cyanobacterial dominance may be partly due to a low degree of control from large generalist zooplankton, as suggested by the negative relationship between cyanobacteria and cladoceran (Ghadouani et al., 2006; Catherine et al., 2008). Cyanobacteria secondary metabolites production may help to explain food selection and avoidance in freshwater ecosystems (Jüttner, 2005). Thus, studying Daphnia sp. behaviour facing different nutrition choices may contribute to explain why some phytoplankton species are favoured and may dominate the phytoplankton community.

Diel vertical migration of zooplankton is a daily pattern of movement in relation to temperature (Lampert and Grey, 2003), light (Stearns, 1975) and predator-prey interactions (De Meester et al., 1995). Usually, the pattern is an evening ascent to surface waters and a morning descent to deep waters. The diel vertical migration of daphnids is associated with considerable metabolic cost (Stich and Lampert, 1984), but plays a key role in predator avoidance. This migration may be motivated by fish semiochemicals (Dodson, 1988; Loose, 1993; Lampert, 1993; De Meester et al., 1995). Thus, daphnids are able to detect kairomones released by fishes (Beklioglu et al., 2006). Other compounds may also modify the behaviour of zooplankton. For instance, organic compounds produced by algae and cyanobacteria can play an attractive and defensive role in aquatic ecosystems (Lass and Bittner, 2002; Fink et al., 2006). Jüttner (2005) showed that diatoms and other phytoplanktonic species damaged by grazers may produce compounds that are toxic and repellent to herbivorous zooplankton (Jüttner, 2005). In a more recent article, Jüttner et al. (2010) showed that the cell disruption of the cyanobacterium Microcystis produces a defense signal, the b-Cyclocitral, that induces an increase in swimming velocity of $D$. magna. As a consequence, the signal induces the escape of the daphnids. Thus, the presence of fish or algae and the production of organic compounds such as kairomones influence Daphnia migration (Beklioglu et al., 2008; Rinke and Petzoldt, 2008; Jüttner et al., 2010; Slusarczyk and Pinel-Alloul, 2010).

The relationships between cyanobacteria and daphnids reflect the typical complexity of prey-predator interactions and much is still unknown. In particular, to our knowledge, the influence of the prey on the spatial displacement of the predator has been poorly studied. Since Daphnia's predators may elicit its migration, one might ask whether its prey (cyanobacteria) may also induce migration of the grazer (daphnids). To address this question, Van Gool and Ringelberg (1996) were the first to use an Y-tube olfactometer with an inflows of water. Their results showed that Daphnia may discriminate between clean water and water that previously contained either Scenedesmus acuminatus or Planktothrix limnetica but not Planktothrix agardhii producing MC. Olfactometers were rarely used in studies on aquatic invertebrates, but such devices were validated by numerous behavioural studies of semiochemical recognition in terrestrial species (Janssen et al., 1990; Scutareanu et al., 1996).

Based on studies on the effects of chemical compounds on terrestrial insects displacements (Dornhaus and Chittka, 2001; Meinwald and Eisner, 2008), of chemical defences against predation (Lass and Spaak, 2003), and on migration of zooplankton stimulated by the presence of kairomones (Rinke and Petzoldt, 2008; Beklioglu et al., 2008; Slusarczyk and Pinel-Alloul, 2010), we explored - with olfactometers adapted to aquatic species - the migration of starved daphnids when exposed to different signals. Unlike other studies (Van Gool and Ringelberg, 1996; Roozen and Lürling, 2001), our design without inflow allowed movement of daphnids in the absence of rheotaxis influence. Thus, the main aim of our study was to observe not only daphnids' first choices, but also daphnids' behaviour over a long time, and to test assumptions on their exploratory ability. The second aim was to explore daphnids' behaviour facing different resources extracted from green algae or cyanobacteria that are potentially attractive or repulsive with a particular attention to MC.

\section{METHODS}

\section{Experimental design}

\section{Origin and culture of organisms}

We used two monoclonal and non-axenic strains of Planktothrix (P.) agardhii isolated from the Base Nautique de Viry, France (Yéprémian et al., 2007) and maintained in the Paris museum collection (PMC). The P. agardhii strain PMC 75.02 produces mainly three variants of microcystins ( $m / z$ 981.6 [D-Asp 3 ]MC-LR; m/z 1024.8 [D-Asp3] MC-RR; and $m / z$ 1045.6 [D-Asp ${ }^{3}$ ]MC-HtyR). The P. agardhii strain PMC 87.02 is a MC-free strain (Yéprémian et al., 2007). We refer to these strains in the following as the MC-strain and the MC-free strain respectively. However, both strains are able to produce other secondary metabolites that may affect Daphnia magna population dynamics (Hulot et al., 2012). Thus, these two strains will allow a comparison among the effects of cyanobacterial compounds. Each strain was cul- 
tured in modified 2 L Duran bottles containing $1 \mathrm{~L}$ of Z8 medium (Kotai, 1972) and inoculated with $100 \mathrm{~mL}$ of an exponential pre-culture. The bottles were placed in growth chambers at $20 \pm 1^{\circ} \mathrm{C}$, and illuminated with cool white fluorescent tubes (L18W/21-840, Osram lumilux Plus Eco; OSRAM GmbH, Munich, Germany) with a 16:8 light:dark cycle, under $10 \pm 2 \mu \mathrm{mol}$ photons $\mathrm{m}^{-2} \mathrm{~s}^{-1}$ (Yéprémian et al., 2007). Growth of the cyanobacteria cultures was monitored by measuring optical density at 436 and $750 \mathrm{~nm}$ every two days with a spectrophotometer (Foy and Smith, 1980). The cultures were stopped at the plateau phase, and the MC-strain and $\mathrm{MC}$-free strain were kept at $-80^{\circ} \mathrm{C}$ for conservation, and thawed $24 \mathrm{~h}$ before use as a treatment. Microcystin-RR (Alexis ${ }^{\circledR}$ Biochemicals, San Diego, CA, USA) was selected as pure toxin whose toxicity mimics an exposure to a less toxic $\mathrm{MC}$ such as the demethyl forms (e.g., $\mathrm{LD}_{50}$ of [D$\mathrm{Asp}^{3} \mathrm{TMC}-\mathrm{LR}$ ranged from 160 to 300 on mouse) (Sivonen and Jones, 1999).

Daphnia magna has a big size and is easily cultured in laboratory. Individuals were isolated from a pond situated at the École Normale Supérieure (Paris, France), and kept in an aquarium with Volvic water (Societé des Eaux de Volvic, Volvic, France) and fed on Scenedesmus obliquus (CCAP 276/6A). This alga, which is known to be a good resource for Daphnia (Lampert, 1987), was cultured at $22 \pm 1^{\circ} \mathrm{C}$ and under $14: 10 \mathrm{~h}$ light-dark cycle in COMBO medium (Kilham et al., 1998).

Our experiments in olfactometers were based on feeding stimulation, so daphnids were starved prior to the experiment. To do so, we isolated adults $D$. magna from stock culture $24 \mathrm{~h}$ prior to the experiments in vials containing pure Volvic (Societé des Eaux de Volvic) water.

\section{Experimental system}

The olfactometer consists of three glass jars connected via a Y-junction and corridors made of silicone tubes (Fig. 1). In one jar, i.e. the introduction jar, daphnids are introduced at the beginning of the experiment and they may eventually return in it. The two other jars are the migration jars containing the treatments and the individuals which can migrate into it. We used a Y-junction to have no asymmetry in our olfactometer. All corridors have the same diameter $(5 \mathrm{~mm})$ and the same length $(50 \mathrm{~mm})$, and the jars have a diameter of $50 \mathrm{~mm}$ and a volume of 100 $\mathrm{mL}$. After filling the whole system with $100 \mathrm{~mL}$ of water, tubes were closed with clips adjoining the Y-junction to

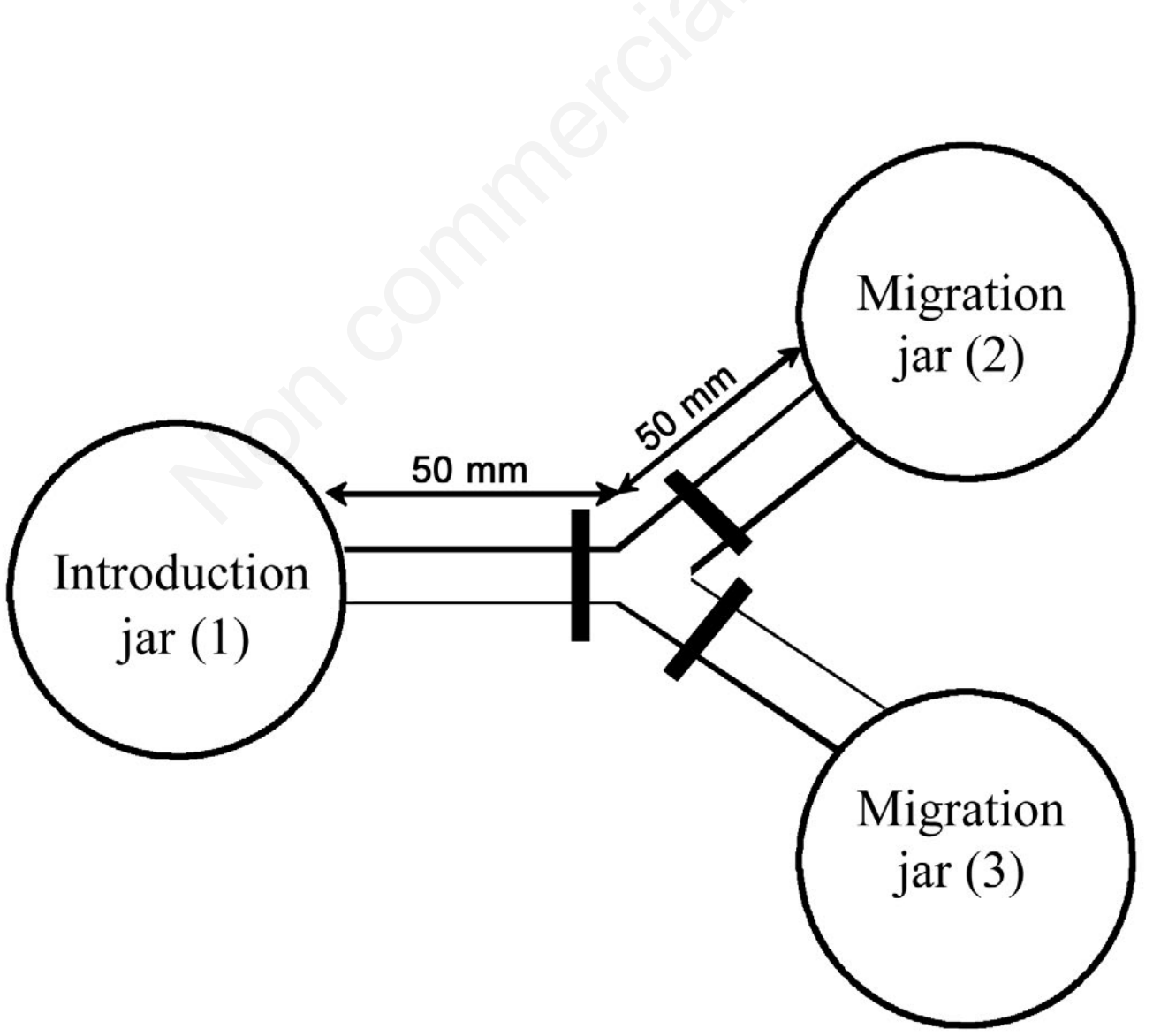

Fig. 1. Olfactometer. Individuals are introduced in an introduction jar (1) and may migrate to the migration jars (2 and 3$)$ that contained the treatment. Clips are represented by black bars at the end of each Y-junction. 
isolate the three parts of the olfactometer (Fig. 1). After removing equivalent volumes of water, we added the corresponding treatments in migration jars. One single starved daphnid was added to the introduction jar, the clips were removed and the movements of the individual were recorded during $1.5 \mathrm{~h}$. This device thus allowed individual daphnids leaving the jar of introduction to choose between the migration jars depending on different treatments. Two 36 watt fluorescent tubes were suspended above the olfactometers and the light intensity arriving on experimental systems was 1500-2000 lux»21-28 $\mu \mathrm{mol}$ photons $\mathrm{m}^{-2} \mathrm{~s}^{-1}$ (PAR). This ensured homogeneous light for each olfactometer. Eight olfactometers were used at the same time to replicate all the experiments. To avoid any bias due to the relative position of the systems, olfactometers rotated at each repetition.

\section{Experiments}

\section{Preliminary experiment}

Our goal was to observe the behaviour of zooplankton in response to olfactory stimuli: we planned to measure the first choice as well as the choice made after some time, allowing exploration. To assess whether the observation lasted long enough (movements of daphnids became rare after $1.5 \mathrm{~h}$ ) to give reliable data, and to ensure that there was no bias in the movements of daphnids due to the device, a preliminary test was conducted. In this test, the migration jars contained pure Volvic water (Societé des Eaux de Volvic) and one adult daphnid starved for $24 \mathrm{~h}$ was introduced in the jar of insertion. Seventeen repetitions with eight systems at the same time were conducted. For this preliminary experiment, we obtained 136 observations of different daphnids during 17 sessions of 90 min each.

\section{Main experiment}

We recorded daphnids' behaviour when they had the choice between i) MC-strain vs water, ii) MC-free strain $v s$ water, iii) pure MC-RR vs water, iv) S. obliquus vs water, v) MC-strain $v s S$. obliquus, vi) MC-free strain $v s$ S. obliquus vii) MC-free strain $v s$ MC-strain, and viii) water $v s$ water as a control. These eight treatments were tested in parallel with eight olfactometers and the tests were repeated 100 times strictly in the same conditions. Thus, we obtained 100 observations of different starved daphnids for each of the eight oppositions of treatments (Fig. 2) and our dataset was composed of 800 observations of displacements during $1.5 \mathrm{~h}$. The water treatment contained pure Volvic (Societé des Eaux de Volvic) water. The density of resource in the treatments with MC-strain, MC-free strain and S. obliquus was calculated so that the final density of phytoplankton was 10 times Daphnia daily carbon requirement $\left(0.2{\mathrm{mg} . \text { day }^{-1}}^{-1}\right.$ (Sim et al., 1994; Lampert, 1987). Treatments were kept at $-80^{\circ} \mathrm{C}$ and thawed 24 hours before use, which disrupted cells. Unlike previous studies (Van Gool and Ringelberg, 1996; Roozen and Lürling, 2001), the present design devoid of filtering step, allowed to have the whole $S$. obliquus and P. agardhii cellular contents directly available to grazers.

The MC-RR treatment volume was calculated to get the same microcystin concentration as in the MC-strain treatment. The MC concentration in MC-strain treatment was $9.6 \mu \mathrm{g}$ eq. MC-RR.L $\mathrm{L}^{-1}$ assessed with a PP2A phosphatase assay (Rivasseau, 1999; Yepremian et al., 2007; Müller et $a l$. , in preparation). In the pure MC-RR treatment, we used purified MC-RR (Alexis ${ }^{\circledR}$ Biochemicals) solubilised with $\mathrm{MeOH}$ diluted at $1 \%$ and conserved at $-20^{\circ} \mathrm{C}$.

We analysed the first choice recorded for all individuals regardless of the migration time (between 0 and 1.5 h) and the position at the end of the observation period (after $1.5 \mathrm{~h}$ ). We refer thereafter to these choices as the first choice and the last choice respectively. For the first choice, daphnids could choose between both treatments. For the last choice, daphnids could either rest in the first choice jar, move to the second treatment jar or come back to the introduction jar. These observations allowed us to study Daphnia's behaviour (exploration, detection, choice) according to the presence or absence of compounds, as well as to test the attractive, repellent or neutral effects of compounds studied.

\section{Statistical analysis}

Two types of analysis were done: i) comparisons of the distribution of daphnids between the treatments for each choice, and ii) comparisons of the distributions of daphnids between the first and the last choices. We used Fisher's exact test with R software. Fisher's exact test is used in the analysis of contingency tables when sample sizes are small. For the first and last choices, we tested the significance of the deviation from a null hypothesis of equal distribution. For the comparison between the first and last choices, we tested the significance of the deviation of the last choice from the first choice. We set significant differences at a threshold of $\alpha=5 \%$ and marginal significance at a threshold of $\alpha=10 \%$.

\section{RESULTS}

The results of the preliminary experiment performed with 135 replicates show that there is no bias in the experimental design (Tab. 1). One replicate was lost because of daphnid's death during the experiment. Tests on the first and last choices did not show significant difference between the number of daphnids present in the two migration jars $(\mathrm{P}=0.57)$. In addition, we did not observe any difference between the distribution of first and last choices (after $1.5 \mathrm{~h}$ ). We observed that $71.8 \%$ of the individuals remained in the introduction jar; $7.4 \%$ of the individuals that left introduction jar returned to it; only $20.7 \%$ of the 
individuals migrated definitely to either of the two treatment jars (Tab. 1).

In the main experiment, according to the treatments, between 66 and $79 \%$ of the individuals stayed in the introduction jar (Tab. 2). Between 0 to $6 \%$ of the individuals left this jar and returned to it later (Tab. 2). Again, there were no significant differences in the treatment water $v s$ water at the first $(\mathrm{P}=0.885)$ and last choices $(\mathrm{P}=0.88)$ (Fig. 2a, Tab. 3) confirming the absence of bias from the device. Similarly, there are no significant differences when daphnids had to choose between MC-RR and water (Fig. 2b, Tab. 3), MC-strain and water (Fig. 2c, Tab. 3), MC-free strain and S. obliquus (Fig. 2e, Tab. 3), and MCfree strain and MC-strain (Fig. 2h, Tab. 3).
When submitted to the treatments MC-strain and $S$. obliquus, at the last choice, there were more daphnids in the jar with $S$. obliquus than in the jar with MC-strain $(\mathrm{P}=0.0007)$ (Fig. 2f, Tab. 3). The change between the first and last daphnids choices is significant $(\mathrm{P}=0.002)$. Indeed, daphnids seem to prefer $S$. obliquus after an exploratory phase. A marginal difference is revealed in the treatment S. obliquus vs water at the first choice (Fig. 2g, Tab. 3) with more daphnids in the jar containing $S$. obliquus than in the jar with water $(\mathrm{P}=0.09)$. The difference in daphnids choice for $S$. obliquus $v s$ water is significant at the last choice $(\mathrm{P}=0.02)$. In the treatment where D. magna have the choice between MC-free strain and water, we also observed a significant effect of the treatment, with a prefer-

Tab. 1. Preliminary experiment. Daphnids' choice in olfactometers with pure Volvic water (Societé des Eaux de Volvic, Volvic, France).

\begin{tabular}{lccccc}
\hline & Motionless $^{\circ}$ & Jar $2^{\#}$ & $\begin{array}{c}\text { No. of daphnids } \\
\text { Jar } 3^{\S}\end{array}$ & Return $^{\wedge}$ & Total \\
\hline First choice & 97 & 21 & 17 & - & 135 \\
Choice after $1.5 \mathrm{~h}$ & 97 & 14 & 14 & 10 & 135 \\
\hline
\end{tabular}

${ }^{\circ}$ Number of individuals that stayed in introduction jar during the experiment; ${ }^{*}$ number of individuals that migrated to the jar of migration $2 ; s_{\text {number of }}$ individuals that migrated to the jar of migration 3; ' number of individuals that returned to jar 1 after leaving it.

Tab. 2. Main experiment. Distribution of individual daphnids after $1.5 \mathrm{~h}$.

\begin{tabular}{|c|c|c|c|c|c|c|c|c|}
\hline Treatments $(\%)$ & $\begin{array}{c}\text { Water } \\
\text { vs water }\end{array}$ & $\begin{array}{l}\text { MC-RR } \\
v s \text { water }\end{array}$ & $\begin{array}{c}\text { MC-Pa } \\
v s \text { water }\end{array}$ & $\begin{array}{c}\text { MC-free } \mathrm{Pa} \\
v s \text { water }\end{array}$ & $\begin{array}{c}\text { MC-free Pa } \\
\quad v s \mathrm{Sc}\end{array}$ & $\begin{array}{c}\mathrm{MC}-\mathrm{Pa} \\
v s \mathrm{Sc}\end{array}$ & $\begin{array}{c}\mathrm{Sc} \\
v s \text { water }\end{array}$ & $\begin{array}{c}\text { MC-Pa } \\
\text { vs } \mathrm{MC}-\text { free } \mathrm{Pa}\end{array}$ \\
\hline Motionless $^{\circ}$ & 71 & 66 & 76 & 73 & 68 & 79 & 73 & 66 \\
\hline With motion ${ }^{\#}$ & 29 & 28 & 23 & 25 & 31 & 19 & 24 & 30 \\
\hline Return $^{\S}$ & 0 & 6 & 1 & 2 & 1 & 2 & 3 & 4 \\
\hline
\end{tabular}

MC-RR, treatment with pure microcystin-RR; MC-Pa, treatment with Planktothrix agardhii microcystin-strain (PMC 75.02); MC-free Pa, treatment with Planktothrix agardhii microcystin-free strain (PMC 87.02); Sc, treatment with Scenedesmus obliquus extracts.

'Daphnids that did not move; "daphnids that moved; ${ }^{\circ}$ daphnids that returned into the introduction jar.

One hundred replicates were realised.

Tab. 3. P values of the Fisher's exact test on the distribution of daphnids among the treatments for each choice, and on the distributions of daphnids between the first and the last choice.

\begin{tabular}{|c|c|c|c|c|c|c|c|c|}
\hline Treatment & $\begin{array}{c}\text { Water } \\
\text { vs water }\end{array}$ & $\begin{array}{l}\text { MC-RR } \\
v s \text { water }\end{array}$ & $\begin{array}{l}\text { MC-Pa } \\
\text { vs water }\end{array}$ & $\begin{array}{c}\text { MC-free } \mathrm{Pa} \\
v s \text { water }\end{array}$ & $\begin{array}{c}\text { MC-free } \mathrm{Pa} \\
\quad \text { vs Sc }\end{array}$ & $\begin{array}{l}\mathrm{MC}-\mathrm{Pa} \\
v s \mathrm{Sc}\end{array}$ & $\begin{array}{c}\mathrm{Sc} \\
v s \text { water }\end{array}$ & $\begin{array}{c}\mathrm{MC}-\mathrm{Pa} \\
\text { vs } \mathrm{MC}-\text { free } \mathrm{Pa}\end{array}$ \\
\hline $\begin{array}{l}\text { Distribution } \\
\text { for first choice }\end{array}$ & 0.88 & 0.77 & 0.32 & 0.02 & 0.77 & 0.88 & 0.09 & 0.77 \\
\hline $\begin{array}{l}\text { Distribution } \\
\text { after } 1.5 \mathrm{~h}\end{array}$ & 0.88 & 0.39 & 0.39 & 0.06 & 0.88 & 0.0007 & 0.02 & 1 \\
\hline $\begin{array}{l}\text { Distribution for first } \\
\text { choice } v s \text { distribution } \\
\text { after } 1.5 \mathrm{~h}\end{array}$ & 1 & 0.2 & 1 & $<0.0001$ & 1 & 0.002 & 0.65 & 0.77 \\
\hline
\end{tabular}

$M C-R R$, treatment with pure microcystin-RR; MC-Pa, treatment with Planktothrix agardhii microcystin-strain (PMC 75.02); MC-free Pa, treatment with Planktothrix agardhii microcystin-free strain (PMC 87.02); Sc, treatment with Scenedesmus obliquus extracts. 
ence for water at the first choice $(\mathrm{P}=0.02)$ and a marginal effect with a preference for the MC-free strain at the last choice ( $\mathrm{P}=0.06)$ (Fig. 2d, Tab. 3). Interestingly, we observed a highly significant inversion between the first and last choices $(\mathrm{P}<0.0001)$ : daphnids migrated preferably at the beginning of the experiment to the jar containing water and finally in the jar with the MC-free strain treatment (Fig. 2d, Tab. 3).

\section{DISCUSSION}

Inspired by olfactometers used with terrestrial and aerial species and by previous studies with aquatic species, we used an aquatic Y-tube olfactometer to study the daphnids' behaviour towards semiochemicals. Preliminary tests of our device showed the absence of bias in our experimental system. Therefore, the differences in distribution observed in the main experiment when daphnids were subjected to different treatments are only due to their choices. Our results showed that D. magna did not exhibit preferences in four situations: MC-RR vs water, MCstrain vs water, MC-free strain vs S. obliquus, and MCstrain vs MC-free strain. Yet, D. magna showed preferences for $S$. obliquus and $\mathrm{MC}$-free strain as an alternative from water, and S. obliquus as an alternative to MC-strain.

These results lead to several conclusions. First, the pure cyanotoxin MC-RR has no positive or repellent effects on daphnids. Therefore, the preference for $S$. obliquus as an alternative for the MC-strain cannot be attributed solely to the production of $\mathrm{MC}$ by the P. agardhii strain. Second, thanks to our design without inflows, we showed that D. magna is able to explore its environment and can modify its choice as a result. At their last choice, daphnids chose the treatment with S. obliquus when they had the choice between this green alga and the MC-strain, and they tended to choose the treatment with S. obliquus extracts when they had the choice between this alga and water. Daphnids being starved, this result shows that, after an exploration phase, they migrated to a nutritious source whatever the species. Indeed, when daphnids had the choice between MC-strain and S. obliquus, the analysis of the movements shows first a homogeneous distribution in both jars of migration but, after $1.5 \mathrm{~h}$, they significantly moved to the jar containing S. obliquus, the resource they were fed on before the experiments. When daphnids had the choice between MC-free strain and water, D. magna preference changed between first and last choice, from water to the MC-free strain. These results show that these organisms might express displacement tropism as suggested by other studies (Van Gool and Ringelberg, 1996; Roozen and Lürling, 2001) and highlight the ability of $D$. magna individuals to explore their environment before making choices.

Van Gool and Ringelberg (1996) concluded from their experiments that D. galeata $\mathrm{x}$ hyalina may be attracted by odours associated with edible algae and not by non-edible algae. In contrast, Roozen and Lürling (2001) did not observe preference of $D$. galeata x hyalina, nor of $D$. pulex or D. magna for the edible alga S. obliquus. However, they showed that the swimming speed of D. magna decreased with increased algal concentration. In the present
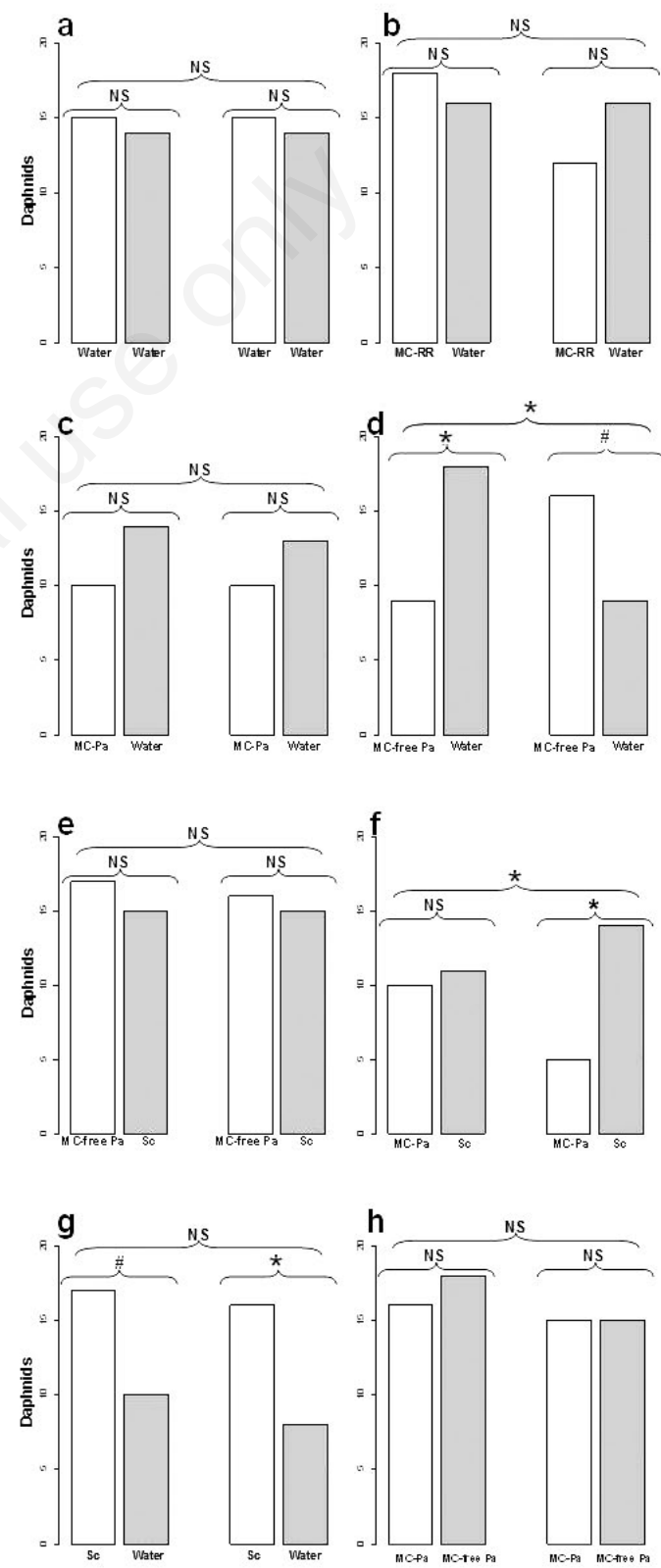

Fig. 2. Distribution of daphnids in the different treatments. In each panel, the first two bars give the first choice and last two bars the last choice. Legends as in Tab. 2. Results of statistical analyses are given as NS when not-significant, * when significant $(\alpha=5 \%)$ and \# when marginally significant $(\alpha=10 \%)$. 
study, we confirmed attraction by nutritious sources, but we also showed that the choice strategy of daphnids might be more complex than those measured in a first-choice test, as they might explore their environment and adapt their response accordingly.

Daphnids do not discriminate between the MC-strain and MC-free strain of P. agardhii. During blooms, the resource selectivity of major herbivorous zooplankton has an important control effect on the dynamic development of cyanobacteria (Catherine et al., 2008). The daphnids' capacity to metabolise MC is of great importance. Thostrup and Christoffersen (1999) showed that microcystin can accumulate in daphnids. This observation and the absence of effects of MC on D. magna migration or discrimination between cyanobacterial strains that produce or not $\mathrm{MC}$ suggest that daphnids may play a role of vectors for the transfer of microcystins to higher trophic levels in the aquatic food web.

Besides the results obtained in this study, the experimental design presented here opens a way for further experiments. Indeed, daphnids migrate vertically in the water column according to light intensity (Stearns, 1975), temperature and food concentration (Lampert, 2003; Kessler and Lampert, 2004), presence of predators (De Meester $e t$ al., 1995), but they may be confronted to variation of these factors at different depths. Their ability to detect kairomones raises the question of their behaviour in presence of multiple semiochemicals. More specifically, in our main experiment we used disrupted cells. With this procedure, S. obliquus and P. agardhii intracellular contents were directly available to grazers. We explicitly manipulated only one compound, MC-RR, but many other compounds in different treatments can influence daphnids. Thus, for a better understanding of daphnids' behaviour and of the effects of cyanobacterial secondary products on the relationship between cyanobacteria and herbivorous zooplankton, ideally we should study the metabolome of both $P$. agardhii strains and test daphnids' preference for cyanobacterial compounds or mixture of compounds with these new aquatic olfactometers.

Pawlik-Skowrońska et al. (2008) showed that the vertical distribution of $P$. agardhii was almost homogeneous in a shallow lake, whereas the MC distribution was not. In this way, potential signals for zooplankton were heterogeneously distributed in water. Horizontal gradients of abiotic conditions, such as light, temperature, dissolved oxygen and $\mathrm{pH}$, are weaker in shallow lakes relative to vertical gradients in deep lakes and are less likely to influence horizontal migration (Burks et al., 2002) than semiochemicals (Kvam and Kleiven, 1995). Heterogeneity in signals emerges also from the presence of predators and compounds produced by macrophytes and this heterogeneity can elicit different responses of zooplankton (Trochine et al., 2009). However, during our experiments, a big number of daphnids did not move and stayed in the introduction jar. This might be due to the absence of water inflows in our experimental device or because daphnids lost their rheotaxis with starvation as suggested by Roozen and Lürling (2001). Our experiments were based on feeding motivation: daphnids were starved with the aim of forcing them to look for food. This stimulation proved to be not enough. Further experiments could manipulate light that attracts daphnids in the absence of predators (Ringelberg, 1987).

\section{CONCLUSIONS}

Our results show that the olfactometer is a promising experimental device for understanding the relationship between phytoplankton and zooplankton and, more generally, the signals that could modify the spatial distribution of zooplankton in aquatic ecosystems. Moreover, our results indicate that daphnids are able to explore their environment in a first phase and express preference for profitable resources in a second phase.

\section{ACKNOWLEDGMENTS}

We thank Selma Maloufi for her help with the protein phosphatase 2A (PP2A) assay, David Carmignac for his assistance during our main experiment, and Minus van Baalen for helpful comments on the manuscript.

\section{REFERENCES}

Abrusán G, 2004. Filamentous cyanobacteria, temperature and Daphnia growth: the role of fluid mechanics. Oecologia 141:395-401.

Arnold DE, 1971. Ingestion, assimilation, survival, and reproduction by Daphnia pulex fed seven species of blue-green. Limnol. Oceanogr. 16:906-920.

Beklioglu M, Altinaya G, Tan CO, 2006. Water level control over submerged macrophyte development in five shallow lakes of Mediterranean Turkey. Arch. Hydrobiol. 166:535556.

Beklioglu M, Gozen AG, Yıldırım F, Zorlu P, Onde S, 2008. Impact of food concentration on diel vertical migration behaviour of Daphnia pulex under fish predation risk. Hydrobiologia 614:321-327.

Brett MT, Goldman CR, 1996. A meta-analysis of the freshwater trophic cascade. P. Natl. Acad. Sci. USA 93:7723-7726.

Burks RL, Lodge DM, Jeppesen E, Lauridsen TL, 2002. Diel horizontal migration of zooplankton: costs and benefits of inhabiting the littoral. Freshwater Biol. 47:343-365.

Carmichael W, 1992. Cyanobacteria secondary metabolites: the cyanotoxins. J. Appl. Microbiol. 72:445-459.

Catherine A, Quiblier C, Yéprémian C, Got P, Groleau A, Vinçon-Leite B, Bernard C, Troussellier M, 2008. Collapse of a Planktothrix agardhii perennial bloom and microcystin dynamics in response to reduced phosphate concentrations in a temperate lake. FEMS Microbiol. Ecol. 65:61-73.

Christoffersen K, Riemann B, Klysner A, Sondergaard M, 1993. Potential role of fish predation and natural populations of 
zooplankton in structuring a plankton community in eutrophic lake water. Limnol. Oceanogr. 38:561-573.

Codd GA, Morrison LF, Metcalf JS, 2005. Cyanobacterial toxins: risk management for health protection. Toxicol. Appl. Pharm. 203:264-272.

De Bernardi R, Giussani G, 1990. Are blue-green algae a suitable food for zooplankton? An overview. Hydrobiologia 200-201:29-41.

De Meester L, Weider LJ, Tollrian R, 1995. Alternative antipredator defences and genetic polymorphism in a pelagic predator-prey system. Nature 378:483-485.

DeMott WR, 1999. Foraging strategies and growth inhibition in five daphnids feeding on mixtures of a toxic cyanobacterium and a green alga. Freshwater Biol. 42:263-274.

Dittmann E, Wiegand C, 2006. Cyanobacterial toxins: occurrence, biosynthesis and impact on human affairs. Mol. Nutr. Food Res. 50:7-17.

Dodson S, 1988. The ecological role of chemical stimuli for the zooplankton: the predator-avoidance behaviour in Daphnia. Limnol. Oceanogr. 33:1431-1439.

Dornhaus A, Chittka L, 2001. Food alert in bumblebees (Bombus terrestris): possible mechanisms and evolutionary implications. Behav. Ecol. Sociobiol. 50:570-576.

Ferrao-Filho AS, Tessier AJ, Demott WR, 2007. Sensitivity of herbivorous zooplankton to phosphorus-deficient diets: testing stoichiometric theory and the growth rate hypothesis. Limnol. Oceanogr. 52:407-415.

Fink P, von Elert E, Jüttner F, 2006. Volatile foraging kairomones in the littoral zone: attraction of an herbivorous freshwater gastropod to algal odors. J. Chem. Ecol. 32:18671881.

Foy RH, Smith RV, 1980. The role of carbohydrate accumulation in the growth of planktonic Oscillatoria species. Brit. Phycol. J. 15:139-150.

Ghadouani A, Pinel-Alloul B, Prepas EE, 2006. Could increased cyanobacterial biomass following forest harvesting cause a reduction in zooplankton body size structure? Can. J. Fish Aquat. Sci. 63:2308-2317.

Gliwicz ZM, Lampert W, 1990. Food thresholds in Daphnia species in the absence and presence of blue-green filaments. Ecolology 71:691-702.

Hansson LA, Carpenter SR, 1993. Relative importance of nutrient availability and food chain for size and community composition in phytoplankton. Oikos 67:257-263.

Hawkins P, Lampert W, 1989. The effect of Daphnia body size on filtering rate inhibition in the presence of a filamentous cyanobacterium. Limnol. Oceanogr. 34:1084-1089.

Hitzfeld BC, Höger SJ, Dietrich DR, 2000. Cyanobacterial toxins: removal during drinking water treatment, and human risk assessment. Environ. Health Persp. 108:113-122.

Hulot FD, Carmignac D, Legendre S, Yéprémian C, Bernard C, 2012. Effects of microcystin-producing and microcystin-free strains of Planktothrix agardhii on long-term population dynamics of Daphnia magna. Ann. Limnol.-Int. J. Lim. 48:337-347.

Janssen A, Hofker CD, Braun AR, Mesa N, Sabelis MW, Bellotti AC, 1990. Preselecting predatory mites for biological-control - the use of an olfactometer. B. Entomol. Res. 80:177181.

Jüttner F, 2005. Evidence that polyunsaturated aldehydes of di- atoms are repellents for pelagic crustacean grazers. Aquat. Ecol. 39:271-282.

Jüttner F, Watson SB, von Elert E, Koster O, 2010. Beta-cyclocitral, a grazer defence signal unique to the cyanobacterium microcystis. J. Chem. Ecol. 36:1387-1397.

Kerfoot WC, Sih A, 1987. Predation: direct and indirect impacts on aquatic communities. University Press of New England, Hanover: 386 pp.

Kessler K, Lampert W, 2004. Fitness optimization of Daphnia in a trade-off between food and temperature. Oecologia 140:381-387.

Kilham SS, Kreeger DA, Lynn SG, Goulden CE, Herrera L, 1998. COMBO: a defined freshwater culture medium for algae and zooplankton. Hydrobiologia 377:147-159.

Kirk KL, Gilbert JJ, 1992. Variation in herbivore response to chemical defenses: zooplankton foraging on toxic cyanobacteria. Ecology 73:2208-2217.

Kotai J, 1972. Instructions for preparation of modified nutrient solution Z8 for algae. Norwegian Institute for Water Research, Oslo: 5 pp.

Kurmayer R, 2001. Competitive ability of Daphnia under dominance of non-toxic filamentous cyanobacteria. Hydrobiologia 442:279-289.

Kvam OV, Kleiven OT, 1995. Diel horizontal migration and swarm formation in Daphnia in response to Chaoborus. Hydrobiologia 307:177-184.

Lampert W, 1987. Laboratory studies on zooplankton-cyanobacteria interactions. New Zeal. J. Mar. Fresh. 21:483-490.

Lampert W, 1993. Ultimate causes of diel vertical migration of zooplankton: new evidence for the predator avoidance hypothesis. Arch. Hydrobiol. Beih. Ergebn. Limnol. 39:79-88.

Lampert W, Grey J, 2003. Exploitation of a deep-water algal maximum by Daphnia: a stable-isotope tracer study. Hydrobiologia 500:95-101.

Lass S, Bittner K, 2002. Facing multiple enemies: parasitised hosts respond to predator kairomones. Oecologia 132:344349.

Lass S, Spaak P, 2003. Chemically induced anti-predator defences in plankton: a review. Hydrobiologia 491:221-239.

Loose CJ, 1993. Lack of endogenous rhythmicity in Daphnia diel vertical migration. Limnol. Oceanogr. 38:1837-1841.

Lürling M, 2003a. Daphnia growth on microcystin-producing and microcystin-free Microcystis aeruginosa in different mixtures with the green alga Scenedesmus obliquus. Limnol. Oceanogr. 48:2214-2220.

Lürling M, 2003b. Effects of microcystin-free and microcystincontaining strains of the cyanobacterium Microcystis aeruginosa on growth of the grazer Daphnia magna. Environ. Toxicol. 18:202-210.

Meinwald J, Eisner T, 2008. Chemical ecology in retrospect and prospect. P. Natl. Acad. Sci. USA 105:4539-4540.

Müller-Navarra DC, Brett MT, Liston AM, Goldman CR, 2000. A highly unsaturated fatty acid predicts carbon transfer between primary producers and consumers. Nature 403:74-77.

Nogueira IC, Lobo-da-Cunha A, Vasconcelos VM, 2006. Effects of Cylindrospermopsis raciborskii and Aphanizomenon ovalisporum (cyanobacteria) ingestion on Daphnia magna midgut and associated diverticula epithelium. Aquat. Toxicol. 80:194-203.

Nogueira IC, Saker ML, Pflugmacher S, Wiegand C, Vasconce- 
los VM, 2004. Toxicity of the cyanobacterium Cylindrospermopsis raciborskii to Daphnia magna. Environ. Toxicol. 19:453-459.

Oberhaus L, Gelinas M, Pinel-Alloul B, Gadhouani A, Humbert JF, 2007. Grazing of two Planktothrix species by Daphnia pulicaria: potential for bloom control and transfer of microcystins. J. Plankton Res. 29:827-838.

Pawlik-Skowronska B, Pirszel J, Kornijow R, 2008. Spatial and temporal variation in microcystin concentrations during perennial bloom of Planktothrix agardhii in a hypertrophic lake. Ann. Limnol.-Int. J. Lim. 44:145-150.

Purdie EL, Samsudin S, Eddy FB, Codd GA, 2009. Effects of the cyanobacterial neurotoxin-N-methylamino-L-alanine on the early-life stage development of zebrafish (Danio rerio). Aquat. Toxicol. 95:279-284.

Reinikainen M, Lindvall F, Meriluoto JAO, Repka S, Sivonen K, Spoof L, Wahlsten M, 2002. Effects of dissolved cyanobacterial toxins on the survival and egg hatching of estuarine calanoid copepods. Mar. Biol. 140:577-583.

Ringelberg J, 1987. Light induced behaviour in Daphnia. Mem. Ist. Ital. Idrobiol. 45:285-323.

Rinke K, Petzoldt T, 2008. Individual-based simulation of diel vertical migration of Daphnia: a synthesis of proximate and ultimate factors. Limnologica 38:269-285.

Rivasseau C, 1999. Development of a bioanalytical phosphatase inhibition test for the monitoring of microcystins in environmental water samples. Anal. Chim. Acta 394:243-257.

Rohrlack T, Christoffersen K, Kaebernick M, Neilan BA, 2004. Cyanobacterial protease inhibitor microviridin $\mathrm{J}$ causes a lethal molting disruption in Daphnia pulicaria. Appl. Environ. Microb. 70:5047-5050.

Rohrlack T, Dittmann E, Henning M, Börner T, Kohl J-G, 1999. Role of microcystins in poisoning and food ingestion inhibition of Daphnia galeata caused by the cyanobacterium Microcystis aeruginosa. Appl. Environ. Microb. 65:737739.

Roozen F, Lurling M, 2001. Behavioural response of Daphnia to olfactory cues from food, competitors and predators. J. Plankton Res. 23:797-808.

Schatz D, Keren Y, Vardi A, Sukenik A, Carmeli S, Börner T, Dittmann E, Kaplan A, 2007. Towards clarification of the biological role of microcystins, a family of cyanobacterial toxins. Environ. Microbiol. 9:965-970.

Scutareanu P, Drukker B, Bruin J, Posthumus MA, Sabelis MW, 1996. Leaf volatiles and polyphenols in pear trees infested by Psylla pyricola. Evidence of simultaneously induced responses. Chemoecology 7:34-38

Sim AT, Ratcliffe E, Mumby MC, Villa-Moruzzi E, Rostas JA,
1994. Differential activities of protein phosphatase types 1 and $2 \mathrm{~A}$ incytosolic and particulate fractions from rat forebrain. J. Neurochem. 62:1552-1559.

Sivonen K, Jones J, 1999. Cyanobacterial toxins, p. 41-111. In: I. Chorus and J. Bartram (eds.), Toxic cyanobacteria in water: a guide to public health significance, monitoring and mangement. E\&FN Spon.

Slusarczyk M, Pinel-Alloul B, 2010. Depth selection and life history strategies as mutually exclusive responses to risk of fish predation in Daphnia. Hydrobiologia 643:33-41.

Stearns SC, 1975. Light responses of Daphnia pulex. Limnol. Oceanogr. 20:564-570.

Stich HB, Lampert W, 1984. Growth and reproduction of migrating and non-migrating Daphnia species under simulated food and temperature conditions of diurnal vertical migration. Oecologia 61:192-196.

Thostrup L, Christoffersen K, 1999. Accumulation of microcystin in Daphnia magna feeding on toxic Microcystis. Arch. Hydrobiol. 145:447-467.

Tillmanns AR, Wilson AE, Pick R, Sarnelle O, 2008. Metaanalysis of cyanobacterial effects on zooplankton population growth rate: species-specific responses. Arch. Hydrobiol. 171:285-295.

Trochine C, Modenutti BE, Balseiro EG, 2009. Chemical signals and habitat selection by three zooplankters in Andean Patagonian ponds. Freshwater Biol. 54:480-494.

Van Gool E, Ringelberg J, 1996. Daphnids respond to algae-associated odours. J. Plankton Res. 18:197-202.

Vanni MJ, 1987. Effects of nutrients and zooplankton size on the structure of a phytoplankton community. Ecology 68 : 624-635.

Vanni MJ, Findlay DL, 1990. Trophic cascades and phytoplankton community structure. Ecology 71:921-937.

Von Elert E, Wolfram T, 2001. Supplementation of cyanobacterial food with polyunsaturated fatty acids does not improve growth of Daphnia. Limnol. Oceanogr. 46:1552-1558.

Wilson AE, Hay ME, 2007. A direct test of cyanobacterial chemical defense: variable effects of microcystin-treated food on two Daphnia pulicaria clones. Methods 52:1467-1479.

Wilson AE, Sarnelle O, Tillmanns AR, 2006. Effects of cyanobacterial toxicity and morphology on the population growth of freshwater zooplankton: meta-analyses of laboratory experiments. Limnol. Oceanogr. 51:1915-1924.

Yéprémian C, Gugger MF, Briand E, Catherine A, Berger C, Quiblier C, Bernard C, 2007. Microcystin ecotypes in a perennial Planktothrix agardhii bloom. Water Res. 41:44464456. 